Comunicação e Sociedade, vol. 7, 2005, pp. 5-8.

\title{
Economia política da comunicação e dos media: novos cruzamentos e triangulações
}

Helena Sousa*

O presente número da revista Comunicação Sociedade é dedicado à Economia Política da Comunicação e dos Media. Ainda que no nosso país esta área esteja a dar os seus primeiros passos no contexto mais amplo das Ciências da Comunicação, há muito que a Economia Política deixou de ser marginal no estudo da comunicação e dos media, tanto nos Estados Unidos como na Europa. O desenvolvimento dos mercados associados às indústrias culturais e a crescente internacionalização das industriais mediáticas e das tecnologias da informação têm demonstrado a relevância teórica da Economia Política e têm apresentado igualmente um conjunto de novos desafios que importa equacionar.

O estudo das comunicações e dos media não é, de facto, mais pensável sem a tentativa de compreensão das estruturas de mercado e das suas articulações com a esfera política, sem a interrogação da propriedade das empresas e dos actores que dominam os mercados nas chamadas sociedades livres, sem a análise cuidada das tendências e das contratendências, das forças e das tensões que sistematicamente reorganizam o poder comunicacional de que as esferas públicas estão dependentes. A Economia Política da Comunicação e dos Media é uma porta de entrada no campo que pode contribuir fortemente para a contextualização de outros saberes e de outras narrativas. Com este volume da Revista Comunicação e Sociedade, pretendemos contribuir para a clarificação de um subcampo que é ainda insuficientemente conhecido.

No sentido de dar resposta a este objectivo, dividimos os artigos temáticos deste número em duas partes. A primeira parte é dedicada à apresentação e ao desenvolvimento de um enquadramento teórico que contribua simultaneamente para a compreensão deste quadro de pensamento e para um melhor entendimento das dinâmicas da comunicação e dos media em Portugal e na Galiza. Na segunda parte dos artigos temáticos, temos um conjunto mais heterogéneo de casos, sectores e problemáticas

\footnotetext{
* Coordenadora do volume (helena@ics. uminho.pt).
} 
sobre a comunicação e os media no nosso país e na (tão próxima) Galiza que são vistos à luz da Economia Política dos Media. Esta perspectiva teórica está longe de dispensar outras, mas parece-nos cada vez mais relevante que outras aproximações não ignorem (também) esta.

Na primeira parte - que compreende os artigos de Graham Murdock, Janet Wasko e Vincent Mosco - ficamos com uma visão dos grandes paradigmas deste denso corpo de literatura. Para além da clarificação interna da disciplina e dos seus principais desafios e mitos, estes textos de abertura contribuem para uma melhor leitura das ténues fronteiras entre a Economia Política, a Ciência Política e a Economia. Paralelamente apontam também para novas possibilidades de relacionamento teórico e empírico com disciplinas (não necessariamente) mais imprevisíveis como os Estudos Culturais, a Geografia, a Antropologia e os Estudos de Género.

Num exercício de grande nitidez, Graham Murdock analisa as principais linhas de pensamento da Economia Política da Comunicação e dos Media e as tradições de que decorrem estes olhares. Definindo as fronteiras entre a Economia e a Economia Política, Graham Murdock examina a cisão interna à Economia Política entre a perspectiva Crítica (mais centrada nas questões da propriedade e do poder) e a Clássica (mais centrada na análise dos mercados e nos mecanismos de competição) que marcou irreversivelmente o desenvolvimento da disciplina. Este autor problematiza as recentes transformações nos mercados da comunicação e dos media na Europa e os mais relevantes desafios e oportunidades com que a disciplina se debate numa fase de emergência de uma esfera pública digital.

Tendo, alternativamente, como ponto de partida a tradição teórica norte-americana da Economia Política da Comunicação e dos Media, Janet Wasko dá-nos conta da sua própria leitura dos fundamentos da disciplina e dos mais relevantes estudos desta área científica. Revela detalhadamente os principais autores, estudos e temas que dão corpo às várias correntes da Economia Política. Fazendo ainda um percurso pelas principais tendências da comunicação e dos media no mercado norte-americano, Janet Wasko estabelece as relações que importa desenvolver entre a Economia Política e outras áreas do saber (por exemplo, Economia, Estudos Culturais e Estudos de Recepção).

Vincent Mosco dedica a sua atenção à Economia Política do ciberespaço e aos mitos que lhe estão associados. O ciberespaço é aqui reflectido como resultado do desenvolvimento mútuo da digitalização e da comercialização, uma vez que a digitalização (com o potencial de uma linguagem universal) expande o processo de comercialização do conteúdo na medida em que alarga as possibilidades de medir, monitorizar, empacotar e reempacotar a informação e o entretenimento. O desenvolvimento simultâneo da digitalização e da comercialização tem contribuído para a integração do sector da comunicação e das tecnologias da informação e para a concentração de poder neste importante sector da vida económica. Vincent Mosco demonstra, com eloquência, que as transformações tecnológicas permitem re-imaginar mudanças revolucionárias, mas que as lógicas económicas e políticas conseguem manter praticamente imutáveis antigos paradoxos e as inesgotáveis tensões. 
A segunda parte dos artigos temáticos deste volume convida-nos a entrar numa realidade que nos é bem mais próxima. A comunicação e os media em Portugal e na Galiza são aqui objecto de análise à luz da Economia Política.

Assim, começamos com um percurso sobre as políticas nacionais para a Sociedade da Informação que nos é apresentado por Lurdes Macedo. Esta autora identifica os desafios que o eventual 'novo' modelo de organização informacional da sociedade coloca a um país como Portugal. Este texto debate a inter-relação da forte penetração das tecnologias da informação e da comunicação com os indicadores de subdesenvolvimento social que o país ainda apresenta. E não deixa de questionar a intervenção política nesta área, nomeadamente no que toca ao desenvolvimento e à implementação de programas específicos para a Sociedade da Informação.

A televisão é considerada em três textos específicos. Helena Sousa e Manuel Pinto apresentam a inédita decisão governamental de atribuir um canal generalista da Radiotelevisão portuguesa à chamada 'sociedade civil' e argumentam que a implementação deste modelo de participação parece estar mais directamente relacionado com questões económicas e financeiras do que com o desenvolvimento de um novo modelo de participação e de cidadania. De resto, e tal como afirma Pedro Jorge Braumann no artigo subsequente, as estratégias das empresas televisivas são fortemente condicionadas pelos seus resultados financeiros. Fora do âmbito da televisão generalista, Dora Mota descreve as políticas recentes para a televisão regional e local em Portugal, integrando-as no contexto das transformações em curso nos media desde finais dos anos oitenta. Argumenta, neste artigo, que a criação de legislação específica para a televisão regional e local nunca foi uma prioridade para os sucessivos governantes. A exiguidade do mercado publicitário foi apresentado como o maior obstáculo, embora pareça evidente a falta de vontade política em abrir mão de um meio tradicionalmente controlado pelo Estado. Assim sendo, a televisão regional permanece - na opinião da autora - acantonada no serviço público que, contrariando as recomendações da entidade reguladora, canalizou a cobertura regional para o cabo.

No âmbito da rádio, uma área de investigação que merece um maior investimento, Rogério Santos dá um contributo de grande relevância. O autor trabalha um conjunto de elementos que ilustram particularmente bem a situação actual da rádio em Portugal. Para além de uma curta história do meio no nosso país, dá informação sobre os grupos de rádio, mercado publicitário, públicos e audiências e políticas de incentivos. No conjunto de tendências e conclusões, o artigo destaca o aumento da liberalização, com a consequente formação de grupos de comunicação mais fortes e inovadores, a associação de partilha de recursos nas estações mais pequenas e os desafios da rádio na Internet. O texto de Rogério Santos salienta ainda as deficiências de serviço público e a precariedade laboral em muitas estações de proximidade.

De seguida, encontramos dois textos relacionados com a imprensa regional e com as políticas governamentais para este subsector. Paulo Ferreira defende que as actuais características do sector são inversamente proporcionais à importância que este tipo de publicações pode, e deve, assumir nas comunidades locais e regionais. Percebe-se a 
consequência deste hiato: sem bons jornais, as comunidades locais e regionais ficam tendencialmente amputadas de boa "informação de proximidade". Independentemente de outros factores que podem contribuir para o entendimento desta situação, este artigo centra a sua atenção na dimensão política do problema, procurando demonstrar que a imprensa local e regional portuguesa tem sido vítima das más decisões, e sobretudo das não decisões, que sobre ela os vários governos têm tomado. Victor Amaral centra a sua análise sobre a imprensa regional no quadriénio 1999-2002, período coincidente com a entrada em vigor de um novo regime de incentivos. Esta análise confronta uma visão proteccionista do Estado, à qual estão 'agarrados' grande parte dos cerca de 900 títulos de imprensa local e regional, com uma visão liberal, que pressupõe novos desafios de inovação e de criatividade empresarial.

Um pouco mais distante da abordagem por subsector (televisão, rádio, imprensa e tecnologias da informação), temos três textos relativos à concentração e aos mecanismos de regulação, problemáticas bem caras à Economia Política dos Media. O primeiro destes artigos é da autoria de Xosé López e dá-nos conta da forte vocação local dos media na Galiza, da sua estrutura empresarial fundamentalmente familiar e das lógicas que presidem aos processos de concentração nesta região. No contexto português, Elsa Costa e Silva apresenta a relação entre as estruturas legais e reguladoras e os mecanismos de concentração dos media em Portugal. A investigadora argumenta que, actuando de uma forma subsectorial, a legislação do sector dos media tem evoluído no sentido de permitir, e mesmo de favorecer, a concentração, não lhe colocando obstáculos objectivos. Por fim, Manuela Espírito Santo analisa um dos (poucos) pontos de convergência dos partidos da coligação (PSD-CDS/PP) do XVI Governo e do Partido Socialista: a extinção da Alta Autoridade para a Comunicação Social (AACS). Na opinião da autora, apesar das muitas fragilidades que a AACS apresenta, esta entidade reguladora dos media revela virtualidades que frequentemente não são reconhecidas.

Concluídos os artigos temáticos sobre a Economia Política dos Media, este volume põe ainda à disposição dos leitores uma importante comunicação de Denis McQuail (Publication in a free society: The problem of accountability), proferido durante a Aula Aberta da 'Cátedra Professor Carlos Lloyd Braga' que lhe foi atribuída pela Universidade do Minho em 2004. Os textos finais desta revista são breves 'Leituras' das obras de Mário Mesquita (O Quarto Equívoco, O Poder dos Media na Sociedade Contemporânea, Coimbra: Minerva Coimbra, 2003) e de Joaquim Fidalgo (Em Nome do Leitor - As Colunas do Provedor do 'Público', Coimbra: Minerva Coimbra, 2004).

No seu conjunto, este volume temático reúne uma série de propostas de reflexão e de pensamento que merecem ser lidas, analisadas, complexificadas e, naturalmente, superadas. Estes textos constituem somente um contributo dos seus autores e da Revista Comunicação e Sociedade do Centro de Estudos de Comunicação e Sociedade para a progressiva ultrapassagem da insipiência científica da Economia Política da Comunicação e dos Media e para o gradual reconhecimento das potencialidades explicativas da disciplina. 